\title{
New mutations in KCNT2 gene causing early infantile epileptic encephalopathy type 57: Case study and literature review
}

\author{
Meryem Alagoz ${ }^{\square}$, Nasim Kherad ${ }^{1}$, Sureyya Bozkurt² and Adnan Yuksel ${ }^{1}$ \\ 1Department of Molecular Biology and Genetics, Genome Centre, Biruni University, Zeytinburnu, Istanbul, Turkey; ${ }^{2}$ stinye University Faculty of \\ Medicine, Maltepe, Zeytinburnu, Istanbul, Turkey
}

Purpose. Early infantile epileptic encephalopathy (EIEE) 57 belongs to a group of encephalopathies with earlyonset and characterised by severe electroencephalogram abnormalities, seizures, developmental delay and intellectual disability. Method. We carried out Whole Exome analysis using Next Generation Sequencing (NGS) and bioinformatic analysis performed to find mutation associated with the patient phenotypes. The effect of the mutation on protein structure analysed by PolyPhen2 and Swissmodel ExPASy. Results. In this study, we evaluated two unrelated Turkish males diagnosed with EIEE type 57 to investigate the genetic cause of this disease. Whole exome sequencing revealed mutations in KCN2 gene, which is a member of Potassium channels (KCN) gene family associated with epileptic encephalopathies. Two mutations, c.545A $>$ T (p.Asn182lle and c.2638C $>A$ (p.Leu880Met) were reported here as a novel mutation. Conclusions. Our findings implicate the genotype-phenotype correlation of these mutations. Furthermore, the computational analysis showed their effect on protein binding site and function suggesting their role in the development of early infantile epileptic encephalopathy 57.

Key words: EIEE, Encephalopathy, Seizure, NGS, KCNT2 gene, Epileptic

Received: 08 May, 2020; revised: 11 June, 2020; accepted: 18 July, 2020; available on-line: 15 September, 2020

凶e-mail: malagoz@biruni.edu.tr

Abbreviations: $\mathrm{EE}$, epileptic encephalopathy; $\mathrm{EEG}$, electroencephalogram; EIEE, Early infantile epileptic encephalopathy; EMG, Electromyography; ESP, exome sequencing project; ExAC, exome aggregation consortium; KCN, Potassium channels; MRI, Magnetic Imaging Resonance; NGS, Next Generation Sequencing; WES, Whole Exome Sequencing

\section{INTRODUCTION}

Early infantile epileptic encephalopathy (EIEE) is autosomal dominant and is identified by phenotypic characteristics including intractable seizures and severe cognitive impairment and/or developmental delay (Berg et al., 2010). Occurrence of the EE (epileptic encephalopathy) was found frequent in some countries (Hino-Fukuyo et al., 2009). Moreover, difficulties of patients' maintenance and care, high possibilities of comorbidities, and short life-span (Khan \& Baradie, 2012) create devastating scenario for patients and their families. Various genetic abnormalities in regulatory proteins and ion channels have been detected as causatives of EE (McTague et al., 2016). Although development of NGS (next generation sequencing) has opened new door into diagnosis of genetic impairments, more than $60 \%$ of EOEE remains undiagnosed. Therefore, diagnosis of other genetic causes must be taken into account to facilitate therapies.

Functional abnormalities in ion channels, particularly potassium $(\mathrm{K}+)$ channels due to mutation in potassium channels gene family $(\mathrm{KCN})$, are shown to contribute to impaired neurological functions (D'Adamo et al., 2013). Developmental and epileptic encephalopathies in the form of refractory seizures and frequent epileptic activity have been reported with KCN mutations (Scheffer et al., 2017). KCN gene family encode broad spectrum of potassium channel subunits that are KCNA1, KCNA2, KCNB1, KCNC1, KCNQ2, KCNQ3, KCNQ5 and KCNT1. 3-9 KCNT1 (Slo2.2 or Slack), together with KCNT2 (Slo2.1 or Slick), belongs to the SLO2 family of $\mathrm{Na}+$-dependent $(\mathrm{K}+)$ channel genes, encoding for poreforming $\alpha$ subunits variably gated by changes in voltage and/or concentrations of intracellular ions or second messengers (Bhattacharjee et al., 2003). KCN2 has been considered as a candidate gene for epilepsy with similar symptoms as that of KCNT1 gene (Ambrosino et al., 2018). Recent study on individual with West syndrome detected association of KCNT2 mutation. with the disease (Gururaj et al., 2017). Although nearly $74 \%$ of the KCNT2 gene homology and hetero- tetrameriation between the subunits in some brain and heart regions has been detected, no previous report indicates the connection between the variants of KCNT2 (SLICK or Slo2.1) tohuman phenotype (Chen et al., 2009; Lim et al., 2014; Lim et al., 2016).

In the present study, we investigated the functional impact of two de novo variants of KCNT2 gene in two unrelated patients with neurodevelopmental disorders.

\section{PATIENTS INFORMATION}

The study has been approved by the ethics committee of Biruni University. Written consent for genetic testing and related data has been obtained from each case's biological parents. However, both family refused to carry out further detailed analysis on family members.

Both individuals were born to noncosanguineous healthy parents of Turkish origin. Individual \#1 is a 6-year-old boy who was born at term with $2.90 \mathrm{~g}$ and normal head circumference. Individual \#2 a 5-year-old boy who was born at term with 2.86 g. Individual \#1 was admitted at Biruni University hospital with inability in speaking and walking which indicated delay in motor development. Magnetic Imaging Resonance (MRI) of the patient, at the age of 2 , showed diffusely thin corpus callosum. Also, both of the lateral ventricles are dilated and partial colpocephaly was detected and patient was diagnosed with refractory epilepsy. Social interaction and 
eye contact was reported to be normal. EEG was performed at the age of 5 and it showed sharp and slow waves in the right frontotemporal region. Further analysis with EMG at the same age detected low amplitude distal motor responses from the lower extremity. The individual \#2 showed normal EEG at the age of 1. Both individuals showed reduced muscle strength (hypotonia) and delayed neural development followed by intractable seizures. Further genetic analysis was recommended to find out the causatives for the presented phenotypic characteristics.

\section{RESULTS}

\section{Genetic analysis}

To find genetic alteration associated with the patient phenotypes, we performed Whole Exome Sequencing to analyse the coding exons and exon-intron boundaries of 18.000 protein coding genes. Genomic DNA preparation, exome capture, and Illumina sequencing (NextSeq platform) were performed as recommended by manufacturer. In brief, Genomic DNA was extracted from whole peripheral blood sample using iPrep PureLink gDNA blood Kit (Invitrogen). Genome Library was prepared with Agilent SureSelect Target Enrichment system (Agilent Technologies, Inc., Santa Clara, CA, USA) and enrichment of coding exons and flanking intronic regions was performed using Agilent SureSelect Human All Exon V6 reagent following the manufacturer's protocol as previously described (Bonnefond et al., 2012) and
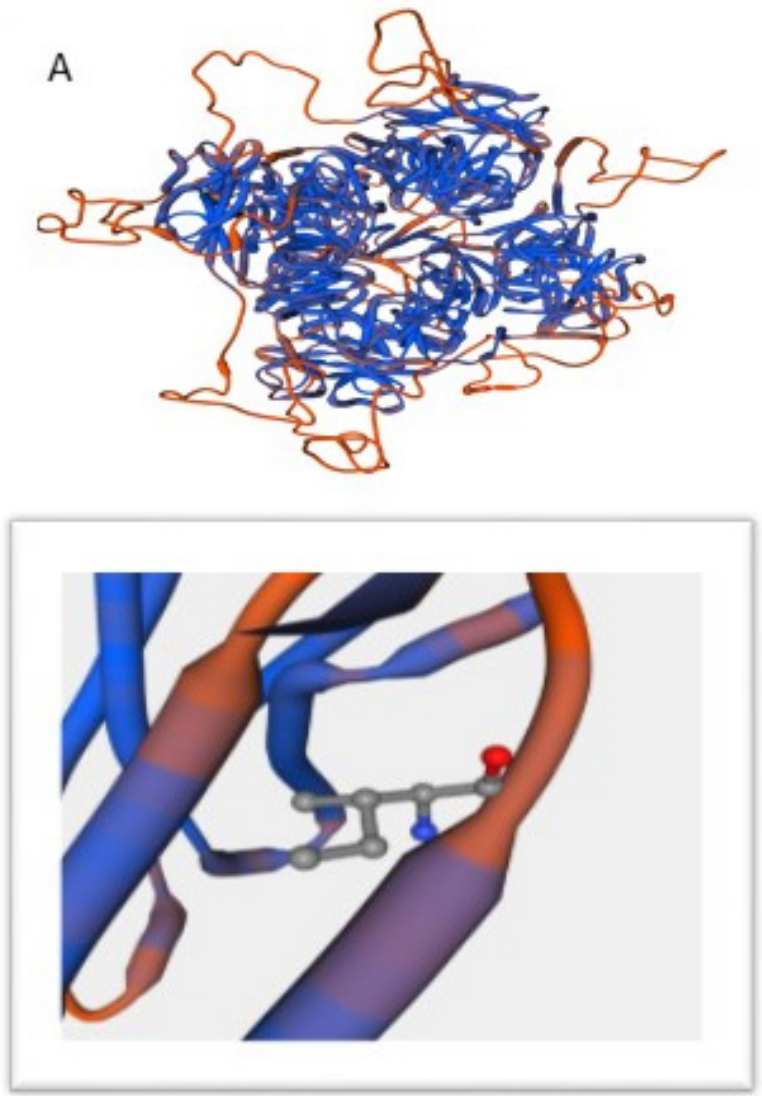

sequencing was performed using an Illumina NextSeq500 system. Sequence reads were mapped to the human genome (GRC38/hg19) using the Burrows-Wheeler Aligner (version 0.6.1; algorithm "BWA-SW"; default parameters) for targeted sequencing data. Variants with frequency more than $1 \%$ in the population were removed. Variants were annotated using Alamut visual, and allele frequency with databases, dbSNP, ExAC (exome aggregation consortium) variants and the 1000 Genomes Project. Disease causality was assessed using ClinVar and ESP (exome sequencing project) variants ExAC (exome aggregation consortium) variants, ESP (exome sequencing project) variants.

The expression of sodium activated potassium channel gene, KCNT2 (Slick), is found in heart and nervous system. Slick is activated by intracellular sodium and possesses nucleotide- binding site that maintains ATPdependent inhibition of channel function and this characteristic affect livability of brain/heart cells which is due to vigorous activities of neurons (Salkoff et al., 2006). The whole exome sequencing revealed heterozygous mutation c.545A $>$ T (p.Asn182Ile) in transcript NM_198503.2 and c. $2638 \mathrm{C}>\mathrm{A}$ (p.Leu880Met) in transcript NM_198503.4 in individual \#1 and \#2 respectively. Based on the family histories and phenotypic characteristics of the disorder in the patients, the above mutations were suggested to be de novo missense variant.

\section{PROTEIN ANALYSIS}

Damage intensity of the mutations was analysed using PolyPhen2 (http://genetics.bwh.harvard.edu/pph2/).
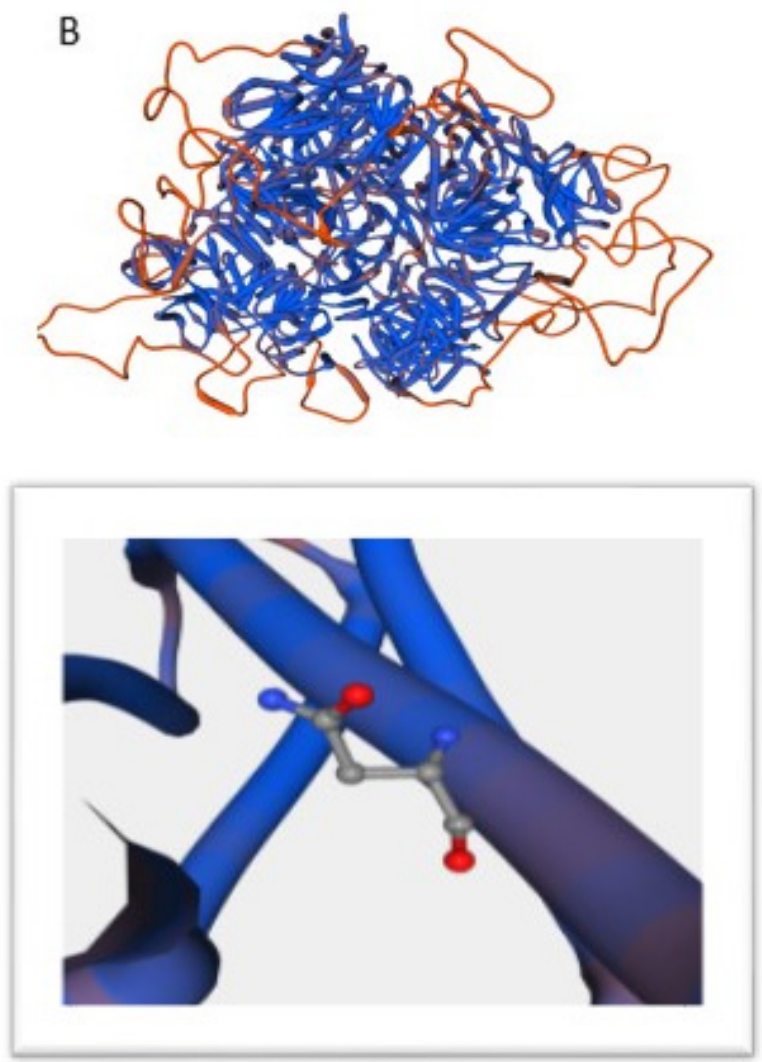

Figure 1. Protein configuration of KCNT2 gene in wild type (A) and case 1 mutations (B).

Figure 1B represents protein configuration change and its binding ligand caused by substitution of Asparagine by Isoleucine. 

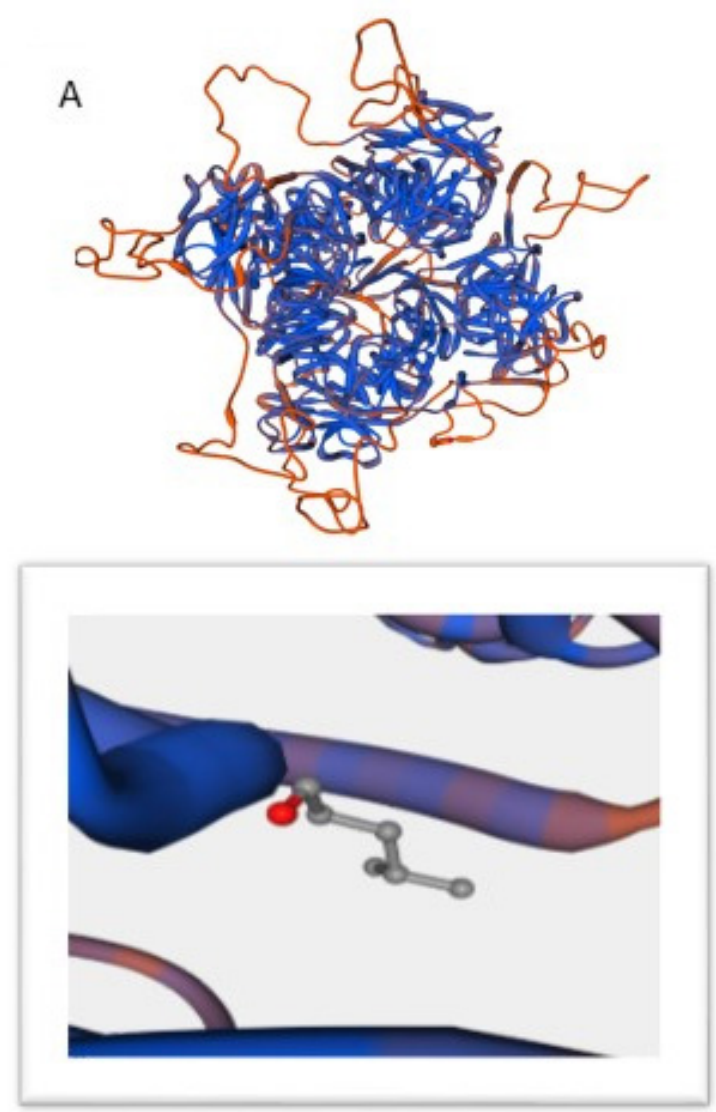
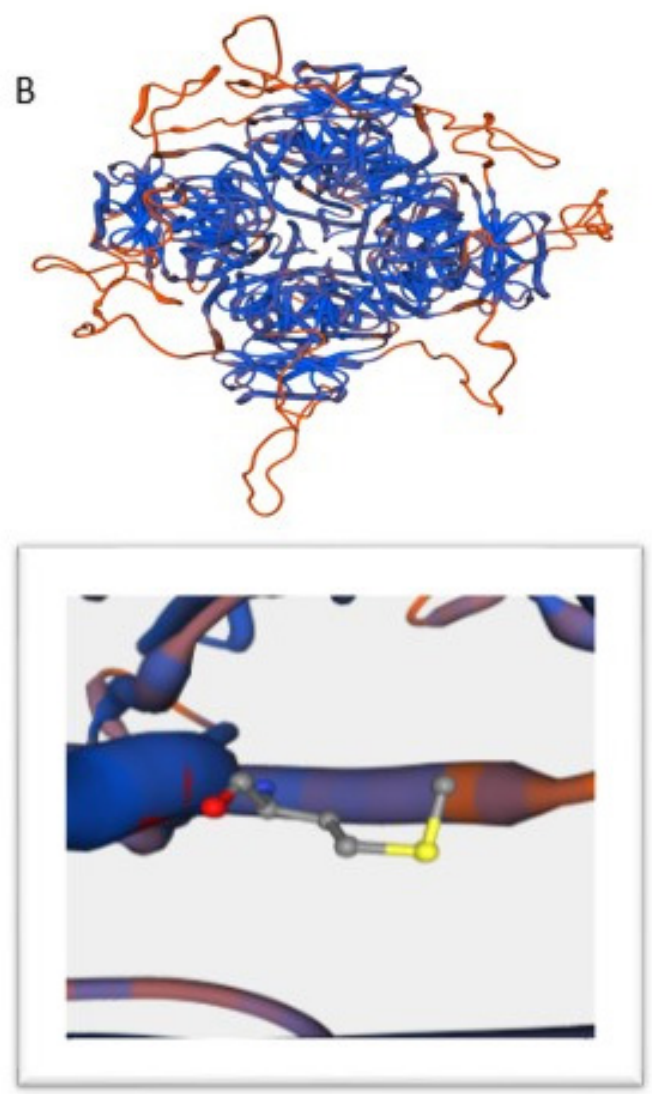

Figure 2. Protein configuration of KCNT2 gene in wild type (A) and case 2 mutations (B).

Figure $2 B$ represents alteration in protein structure and binding sites due to substitution of leusine by methionine

N182I and L880M substitutions are shown to be probably damaging (score 0.984 and 0.989 respectively). Mutation taster program (www.mutationtaster.org/) showed that both mutations cause change in protein function and are disease causing. Following the findings, 3D protein structure analysis by swissmodel expasy (https:// swissmodel.expasy.org/interactive) showed conformational changes in protein and its binding sites (Fig. 1 and Fig. 2). The position was shown in S4-S5 for both mutations which could possibly affect regulators of conductance of potassium (RCK) domains which were previously introduced (Bhattacharjee et al., 2003; Salkoff et al., 2006).

\section{DISCUSSION}

Early Infantile Epileptic Encephalopathy (EIEE) is characterized as neurological disorder and patients show seizures and tonic spasms at the first few months of life. EIEE type 57 has been previously reported in patients with KCNT2 gene mutations (Gururaj et al., 2017). In this paper, we reported two patients of similar phenotypes with different mutation locations on KCNT2 gene. Although the variants' position was not same (N182I and L880M), computational analysis of data from Whole Exome sequencing presented possibly similar damaging effects on protein function and its binding sites. As both patients presented epileptic seizure and developmental delay in nervous system, we deduced the phenotypic abnormality to have been caused by ATP-dependent potassium channels' dysfunction. Although the clinical data due to lack of patients' family cooperation for further studies are not sufficient to present strong case, previous findings on other patients showed connection between KCNT2 gene impairment and EIEE57. Therefore, further investigation of the novel mutations in relation with the development of EIEE57 and patients' clinical outcome is strongly recommended.

\section{REFERENCES}

Ambrosino P, Soldovieri MV, Bast T, Turnpenny PD, Uhrig S, Biskup S, Lemke JR (2018) De novo gain-of-function variants in KCNT2 as a novel cause of developmental and epileptic encephalopathy. Ann Neurol 83: 1198-1204. https://doi.org/10.1002/ana.25248

Berg AT, Berkovic SF, Brodie MJ, Buchhalter J, Cross JH, van Emde Boas W, Engel J, French J, Glauser TA, Mathern GW, Moshé SL, Nordli D, Plouin P, Scheffer IE (2010) Revised terminology and concepts for organization of seizures and epilepsies: report of the ILAE Commission on Classification and Terminology 2005-2009. Epilepsia 51: 676-85. https://doi.org/10.1111/j.15281167.2010.02522.x

Bhattacharjee A, Joiner WJ, Wu M, Yang Y, Sigworth FJ, Kaczmarek LK (2003) Slick (Slo2.1) a rapidly-gating sodium-activated potassium channel inhibited by ATP. J Neurosci 23: 11681-11691. https://doi. org/10.1523/jneurosci.23-37-11681.2003

Bonnefond A Philippe J Durand E Dechaume A Huyvaert M Montagne L, Marre M, Balkau B, Fajardy I, Vambergue A, Vatin V, Delplanque J, le Guilcher D, de Graeve F, Lecoeur C, Sand O, Vaxillaire M, Froguel P (2012) Whole-exome sequencing and high throughput genotyping identified KCNJ11 as the thirteenth MODY gene. Brusgaard K ed. PLoS ONE 7: e37423. https://doi. org/10.1371/journal.pone.0037423

Chen H, Kronengold J, Yan Y, Gazula V-R, Brown MR, Ma L, Ferreira G, Yang Y, Bhattacharjee A, Sigworth FJ, Salkoff L, Kaczmarek LK (2009) The N-terminal domain of Slack determines the formation and trafficking of Slick/Slack heteromeric sodium-ac- 
tivated potassium channels. I Neurosci 29: 5654-5665. https://doi. org/10.1523/jneurosci.5978-08.2009

D’Adamo MC, Catacuzzeno L, Di Giovanni G, Franciolini F, Pessia M (2013) K+ channelepsy: progress in the neurobiology of potassium channels and epilepsy. Frontiers Cell Neurosci 7. https://doi. org/10.3389/fncel.2013.00134

Gururaj S, Palmer EE, Sheehan GD, Kandula T, Rebecca Macintosh R, Ying K, Morris P, Tao J, Dias K-R, Zhu Y, Dinger ME, Cowley MJ, Kirk ED, Roscioli T, Sachdev R, Duffey ME, Bye A, Bhattacharjee A (2017) A de novo mutation in the sodium-activated potassium channel KCNT2 alters ion selectivity and causes epileptic encephalopathy. Cell Rep 21: 926-933. https://doi.org/10.1016/j. celrep.2017.09.088

Hino-Fukuyo N, Haginoya K, Iinuma K, Uematsu M, Tsuchiya S (2009) Neuroepidemiology of West syndrome and early infantile epileptic encephalopathy in Miyagi Prefecture Japan. Epilepsy Res 87: 299-301. https://doi.org/10.1016/j.eplepsyres.2009.09.012

Khan S, Al Baradie R (2012) Epileptic encephalopathies: an overview. Epilepsy Res Treat 403592. https://doi:10.1155/2012/403592

McTague A, Howell KB, Cross JH, Kurian MA, Scheffer IE (2016) The genetic landscape of the epileptic encephalopathies of infancy and childhood. Lancet Neurol 15: 304-316. https://doi.org/10.1016/ s1474-4422(15)00250-1

Lim CX, Ricos MG, Dibbens LM, Heron SE (2016) KCNT1 mutations in seizure disorders: the phenotypic spectrum and functional effects. J Med Genet 53: 217-225. https://doi.org/10.1136/jmedgenet-2015-103508

Lim ET, Würtz P, Havulinna AS, Palta P, Tukiainen T, Rehnström K, Esko T, Mägi R, Inouye M, Lappalainen T, Chan Y, Salem RM, Lek M, Flannick J, Sim X, Manning A, Ladenvall C, Bumpstead S, Hämäläinen E, Aalto K, Maksimow M, Salmi M, Blankenberg S, Ardissino D, Shah S, Horne B, McPherson R, Hovingh GK, Reilly MP, Watkins H, Goel A, Farrall M, Girelli D, Reiner AP, Stitziel NO, Kathiresan S, Gabriel S, Barrett JC, Lehtimäki T, Laakso M, Groop L, Kaprio J, Perola M, McCarthy MI, Boehnke M, Altshuler DM, Lindgren CM, Hirschhorn JN, Metspalu A, Freimer NB, Zeller T, Jalkanen S, Koskinen S, Raitakari O, Durbin R, MacArthur DG, Salomaa V, Ripatti S, Daly MJ, Palotie A, Sequencing Initiative Suomi (SISu) Project (2014) Distribution and medical impact of loss-of-function variants in the Finnish founder population. PLoS Genet 10: e1004494. https://doi.org/10.1371/journal.pgen.1004494

Salkoff L, Butler A, Ferreira G, Santi C, Wei A (2006) High-conductance potassium channels of the SLO family. Nat Rev Neurosci 7: 921-931. https://doi.org/10.1038/nrn1992

Scheffer IE, Berkovic S, Capovilla G, Connolly MB, French J, Guilhoto L, Hirsch E, Jain S, Mathern GW, Moshé SL, Nordli DR, Perucca E, Tomson T, Wiebe S, Zhang Y-H, Zuberi SM (2017) ILAE classification of the epilepsies: Position paper of the ILAE Commission for Classification and Terminology. Epilepsia 58: $512-$ 521. https://doi.org/10.1111/epi.13709 